\title{
AVALIAÇÃO DA INFLUÊNCIA DE COBERTURA DE ALGINATO NA SECAGEM DE MAÇÃ FUJI
}

\author{
L. T. GONÇALVES ${ }^{1}$, L. P. $\operatorname{MUSSI}^{1}$, L. O. PRATES ${ }^{1}$, L. L. GLÓRIA ${ }^{1}$, A. R. AVELAR ${ }^{1}$ \\ ${ }^{1}$ Universidade Estadual do Norte Fluminense Darcy Ribeiro, Laboratório de Tecnologia de \\ Alimentos, Centro de Ciências \\ *e-mail: leticiatinoco@hotmail.com
}

\begin{abstract}
RESUMO
A maçã apresenta alto teor de umidade e é rica em fitoquímicos. O escurecimento enzimático ocorre em decorrência da oxidação dos compostos fenólicos, que formam pigmentos escuros alterando a aparência e propriedades organolépticas do produto. A Vitamina $\mathrm{C}$ pode ser usada como conservante de alimentos em biofilme de cobertura, formando uma barreira contra umidade e gases. Em conjunto a esses métodos, a secagem com ar quente combinada com micro-ondas pode ser utilizada para gerar um produto desidratado em menor tempo de processo, com ação enzimática reduzida, características finais mais atrativas e menores perdas nutricionais. Este trabalho avaliou o efeito de biofilmes de alginato com e sem extrato de laranja na secagem de maçã com ar quente combinado com micro-ondas $\left(60^{\circ} \mathrm{C}\right.$ e $\left.180 \mathrm{~W}\right)$. Os resultados indicaram que a utilização do biofilme de alginato, com ou sem extrato, influenciou a secagem, pois quando comparado com o controle, o tempo de processo para atingir umidade de equilíbrio foi maior. Assim, o recobrimento da maçã com o biofilme desidratada poderá incentivar a comercialização do produto uma vez que reduz alterações indesejáveis provocadas por enzimas oxidativas.
\end{abstract}

\section{INTRODUÇÃO}

A maçã é o fruto da árvore Pyrus malus, apresenta um elevado teor de umidade $(85 \%$ em média) e é rica em fitoquímicos como carotenoides, flavonoides e polifenóis, que provocam as reações de escurecimento enzimático (LU, 2000; TACO, 2011; IGLESIAS, 2012).

Essa reação é um dos principais problemas na indústria de alimentos. Ocorre através da degradação oxidativa dos compostos fenólicos pela atuação das enzimas polifenoloxidase e peroxidase. $\mathrm{O}$ produto final da oxidação é a quinona, que forma pigmentos escuros insolúveis, denominados melaninas. A ação dessas enzimas é acompanhada de mudanças indesejáveis na aparência e nas propriedades organolépticas do produto, resultando na diminuição da vida de prateleira e do valor de mercado (TOMÁSBARBERÁN, 2001; LUPETTI et al., 2005; ARAUJO, 2008).

A prevenção da oxidação em tecidos vegetais pode ser realizada por: inativação térmica utilizando calor, diminuição ou remoção do substrato enzimático (oxigênio), redução do $\mathrm{pH}$ ótimo para o desenvolvimento das enzimas e adição de substâncias redutoras (ácido ascórbico ou ácido nítrico) que inibam a ação das enzimas ou previnam a formação da melanina. $\mathrm{O}$ ácido ascórbico (Vitamina $\mathrm{C}$ ) é reconhecido por sua ação redutora e sua contribuição nutricional, podendo ser usado como extrato e funcionando como um conservante natural na indústria de alimentos (ESCOBEDO-AVELLANEDA et al., 2014). 
O uso de biofilmes pode ser utilizado com a finalidade de preservar a qualidade e prolongar a vida de prateleira de frutas e hortaliças. São definidos como: cobertura (fina camada contínua formada diretamente na superfície do produto) ou como filme (preparado separadamente). São preparados a partir de materiais biológicos, além de serem não poluentes, biodegradáveis e apresentarem baixo custo, tanto de materiais como de processo. São feitos à base de polissacarídeos (celulose, amido e seus derivados, alginato, quitosana, pectina e gomas), e apresentam uma barreira à umidade mínima, devido à natureza hidrofílica dos mesmos, e aos gases, preservando assim os alimentos. (LAZARIDES et al., 2007; LAROTONDA, 2007; LIN \& ZHAO, 2007).

$\mathrm{O}$ alginato proporciona alta viscosidade aparente, mesmo com baixas concentrações, devido ao seu alto peso molecular e rígida estrutura. Uma de suas propriedades é a capacidade de formar géis termoestáveis fortes ao reagir com cátions polivalentes, principalmente íons cálcio. Dessa forma, a presença desses aditivos pode garantir a manutenção da cor e do sabor, reduzindo a oxidação, a descoloração e, consequentemente, a carga microbiana (LIN \& ZHAO, 2007; ANDRADE, 2008).

A secagem é uma operação unitária que pode diminuir a ação de enzimas, como a polifenoloxidase. É uma técnica de conservação de alimentos que remove água ou outro líquido na forma de vapor para o ar não saturado. Apresenta vantagens como: facilidade na conservação do produto, proteção contra microrganismos, redução do peso e volume do produto e oferta de produto em qualquer época do ano. A utilização de secagem com ar quente combinada com micro-ondas pode gerar um produto em menor tempo quando comparado com a secagem convencional, com características finais mais atrativas e menores perdas nutricionais (RAGHAVAN et al., 2005;
FELLOWS, 2006; PEREIRA, 2007; LOPES, 2013)

Diante do exposto, o objetivo deste trabalho foi avaliar a influência do recobrimento de maçãs fatiadas com biofilmes comestíveis à base de alginato de sódio, com e sem extrato de laranja, no processo de secagem a ar quente combinado com micro-ondas.

\section{MATERIAL E MÉTODOS}

\subsection{Matéria-Prima}

Maçãs Fuji e laranjas Pêra foram obtidas no comércio local de Campos dos Goytacazes, RJ, e selecionadas de acordo com as condições de estrutura (tamanho e largura semelhantes) e grau de maturação (coloração da casca). As análises foram realizadas no Laboratório de Tecnologia de Alimentos (LTA/ CCTA/ UENF).

\subsection{Preparação Do Extrato Da Laranja}

As laranjas foram sanitizadas $(100$ $\mathrm{mg} / \mathrm{L}$ de hipoclorito de sódio a 5\%), descascadas e a porção comestível desintegrada em multiprocessador de frutas e verduras (Philco). Foi utilizada uma alíquota de $300 \mathrm{~g}$ da polpa desintegrada. Adicionou-se água destilada $(1: 2 \mathrm{p} / \mathrm{v})$ à polpa e filtrou-se a solução. $\mathrm{O}$ filtrado, após a adição de $30 \mathrm{~mL}$ de água destilada, foi submetido à agitação permanente, a temperatura ambiente por 20 min. $O$ extrato aquoso resultante foi concentrado sob pressão reduzida $(760,0$ $\mathrm{mmHg}$ ) a $55^{\circ} \mathrm{C}$ em rotaevaporador (IKA RV 10 - digital) e o volume final diluído para 50 mL (MELO et al., 2008).

\subsection{Preparação Do Biofilme E Recobrimento}

A solução de biofilme de alginato de sódio foi preparada adicionando-se água destilada à temperatura ambiente, sob agitação constante até completa dissolução do biopolímero. Posteriormente, o extrato da 
laranja a 5\% foi incorporado nas soluções destes biofilmes.

Foram escolhidas 3 maçãs aleatoriamente, estas foram higienizadas e sanitizadas $(100 \mathrm{mg} / \mathrm{L}$ de hipoclorito de sódio a 5\%). Em seguida foi realizado o corte das fatias, 2,5 $\mathrm{mm}$ de espessura, em um fatiador de frios elétrico (Gural, modelo GLP-330, Paraná, Brasil). Posteriormente, as maçãs foram imersas, por 5 minutos, nas soluções de recobrimento comestível e depois em solução de cloreto de cálcio (Synth) a $0,1 \mathrm{M}$, durante 10 minutos, para gelificação do biopolímero e formação do filme.

\subsection{Processo De Secagem Da Maçã}

Os experimentos de secagem com ar quente combinado com micro-ondas foram realizados em um forno doméstico de microondas (Brastemp, modelo BMC38-A), com $750 \mathrm{~W}$ de potência nominal máxima e 38 litros de volume adaptado a um sistema de ar quente. Após realizar o pré-tratamento (recobrimento), as amostras foram distribuídas em bandejas de polipropileno com tela de fibra de vidro revestida com teflon, e colocadas no equipamento de secagem. Foram submetidas à secagem com temperatura do ar de $60{ }^{\circ} \mathrm{C}$, vazão do ar (medida na saída do tubo de exaustão) de 1 $\mathrm{m}^{3} /$ min e potencia aplicada de $180 \mathrm{~W}$.

Foram realizados 3 tratamentos, (1) alginato $3 \%$ sem extrato de laranja; (2) alginato $3 \%$ com extrato de laranja; (3) controle (fatias in natura). As curvas de secagem foram determinadas pelo método gravimétrico, pesando as amostras a cada 5 minutos na primeira hora e a cada 10 minutos até atingir peso constante, com auxílio de balança semianalítica (Shimadzu, modelo UX4200H, Filipinas).

\subsection{Sólidos Solúveis}

O teor de sólidos solúveis foi determinado por um refratômetro de bancada (Quimis, Q-109B) (AOAC, 1998).

\subsection{Potencial Hidrogeniônico}

O Potencial Hidrogeniônico $(\mathrm{pH})$ foi determinado conforme as Normas Analíticas do Instituto Adolfo Lutz (1985).

\subsection{Umidade}

A determinação do teor de umidade das amostras foi realizada pelo método da AOAC (1998), em estufa (Marconi, MA-033) à pressão atmosférica e a $105^{\circ} \mathrm{C}$ até atingir peso constante.

\subsection{Atividade De Água}

A determinação da atividade de água (Aw) foi realizada a $25{ }^{\circ} \mathrm{C}$ empregando-se o instrumento Aqualab (modelo CX-2TDecagon), pelo método do ponto de orvalho à temperatura constante.

\subsection{Análise De Cor}

As medidas de cor nas maçãs in natura, recobertas e secas foram realizadas por um espectrofotômetro portátil (Hunterlab Miniscan Spectrophotometer Plus, iluminante). A cor foi expressa pelo sistema de coordenadas L* $\mathrm{a}^{*}$ e $\mathrm{b}^{*}$ definido pela CIE (1976). O parâmetro L* indica a luminosidade (branco a preto), o parâmetro a* representa o índice de saturação vermelha (vermelho a verde) e o parâmetro $b^{*}$ indica $o$ índice de saturação amarelo (amarelo a azul). A leitura foi realizada diretamente sobre a superfície em triplicata.

\subsection{Análise Estatística}

Os dados das analises físico-químicas foram submetidos à análise da variância (ANOVA, $p \leq 0,05$ ) e teste tukey pelo programa estatístico STATISTIC 5.5.

\section{RESULTADOS E DISCUSSÃO}

Os valores médios da caracterização físico-química das maçãs Fuji in natura e da fruta desidratada após secagem com ar quente 
combinada com micro-ondas podem ser observados na Tabela 1.

Tabela 1 - Caracterização físico-química das maçãs recobertas e controle, antes (X, Aw, SST e pH) e após (X e Aw) a secagem, de acordo com os ensaios (E).

\begin{tabular}{ccccccc}
\hline \multirow{2}{*}{$\mathbf{E}$} & \multicolumn{3}{c}{ Recobertas } & \multicolumn{2}{c}{ Secas } \\
\cline { 2 - 6 } & $\mathbf{X ~ ( \% )}$ & $\mathbf{A w}$ & $\mathbf{S S T}\left({ }^{\mathbf{0}} \mathbf{B r i x}\right)$ & $\mathbf{p H}$ & $\mathbf{X ~ ( \% )}$ & $\mathbf{A w}$ \\
\hline $\mathbf{1}$ & $89,91 \pm 0,20^{\mathrm{a}}$ & $0,99 \pm 0,00^{\mathrm{a}}$ & $7,33 \pm 0,47^{\mathrm{b}}$ & $4,28 \pm 0,00^{\mathrm{a}}$ & $13,36 \pm 0,56^{\mathrm{a}}$ & $0,40 \pm 0,00^{\mathrm{a}}$ \\
$\mathbf{2}$ & $89,92 \pm 0,24^{\mathrm{a}}$ & $0,99 \pm 0,00^{\mathrm{a}}$ & $7,33 \pm 0,05^{\mathrm{b}}$ & $4,11 \pm 0,01^{\mathrm{b}}$ & $14,94 \pm 0,36^{\mathrm{a}}$ & $0,41 \pm 0,00^{\mathrm{a}}$ \\
$\mathbf{3}$ & $84,45 \pm 0,76^{\mathrm{b}}$ & $0,98 \pm 0,00^{\mathrm{b}}$ & $12,57 \pm 0,05^{\mathrm{a}}$ & $4,03 \pm 0,03^{\mathrm{c}}$ & $9,58 \pm 0,89^{\mathrm{b}}$ & $0,29 \pm 0,01^{\mathrm{b}}$ \\
\hline
\end{tabular}

$1=$ biofilme de alginato $3 \%$ sem extrato; 2 = biofilme de alginato $3 \%$ com extrato; $3=$ controle; $\mathrm{X}=$ umidade, $\mathrm{Aw}=$ atividade de água, $\mathrm{SST}=$ sólidos solúveis totais e $\mathrm{pH}=$ potencial hidrogeniônico.

Médias seguidas de mesma letra na vertical não diferem estatisticamente entre si, pelo teste tukey $(\mathrm{p} \leq 0,05)$.

O teor médio de umidade inicial da maçã in natura no controle foi de $84,45 \%$, valor semelhante ao citado pela TACO (2011) de $84,3 \%$ para maçãs Fuji cruas. As maçãs in natura recobertas com alginato $3 \%$ com e sem extrato apresentaram umidade superior ao controle e os valores não diferiram estatisticamente entre si $(89,91$ e $89,92 \%)$.

Após a secagem o teor médio de umidade encontrado no controle foi de $9,58 \%$, valor próximo aos $10 \%$ estabelecido por GOULARTE et al. (2010). Nas maçãs secas, recobertas com alginato $3 \%$ com e sem extrato, os valores estatísticos estiveram de acordo com as maçãs in natura valores estatisticamente próximos entre si $(13,36 \%$ e $14,94 \%)$.

A atividade de água da maçã in natura no controle foi de 0,988 , semelhante ao valor citado por MORENO et al. (2013) de 0,991. Este valor caracteriza frutas e vegetais frescos, sendo estes susceptíveis a deterioração microbiana. A Aw da maçã seca no controle foi 0,296 . Todos os resultados de Aw nas amostras analisadas foram próximos entre si, em torno de 0,401 nas amostras secas. Este teor está relacionado com o baixo conteúdo de umidade, devido ao processo de secagem, podendo este produto ser considerado seguro contra degradações microbiológicas. $\mathrm{O}$ valor encontrado foi inferior ao recomendado para produtos desidratados que é de 0,6. Entre uma mesma variedade de maçãs podem ocorrer diferenças de atividade de água (Aw), que são decorrentes do local e época de plantio, época de colheita e do estágio de maturação da fruta (BOBBIO e BOBBIO, 2001; DAMODARAN et al., 2010).

Os valores médios de sólidos solúveis (SST) são utilizados como medida indireta do teor de açúcares. À medida que o teor de açúcar aumenta (efeito característico da desidratação) este valor irá aumentar. (SANTOS et al., 2013). Os teores de sólidos totais da amostra in natura foram em média $12,57^{\circ}$ Brix. SANTOS et al. (2013) encontrou $11,0^{\circ}$ Brix e LOPES et al. (2011) encontrou 13,8 , em seus experimentos. Nos tratamentos da amostra com alginato $3 \%$ com e sem extrato foi verificado que os valores não diferiram estatisticamente entre si (7,01 e 7,3 ${ }^{\circ}$ Brix), mostrando assim que a adição do extrato não interferiu no teor de sólidos solúveis totais da amostra. $\mathrm{Na}$ amostra controle desidratada, o valor de sólidos totais foi de 54,4 ${ }^{\circ}$ Brix. SANTOS et al. (2013) encontrou um valor superior na maçã desidratada, 69,0 ${ }^{\circ}$ Brix. Observa-se que em todos os tratamentos houve um aumento considerável nos sólidos totais, ou seja, aumento de concentração, comprovando assim a eficiência do processo de secagem

$\mathrm{O} \mathrm{pH}$ antes da secagem apresentou valores médios de 4,03 para a maçã controle, 4,28 para maçã recoberta sem extrato e 4,11 
para a maçã recoberta com extrato. Estes resultados estão semelhantes aos citados por SELMO et al. (1996), valores de 4,06 e por MOURA et al. (2007), valores de 4,01, ambos para a maçã in natura. Esta característica ácida da maçã proporciona maior estabilidade do produto.

Os resultados obtidos pela análise de cor estão descritos na tabela 2 .

Tabela 2 - Resultados da análise de cor das maçãs recobertas e controle antes e após a secagem de acordo com os ensaios (E).

\begin{tabular}{ccccccc}
\hline & \multicolumn{3}{c}{ Recobertas } & \multicolumn{3}{c}{ Secas } \\
\cline { 2 - 7 } $\mathbf{E}$ & $\mathbf{L}^{*}$ & $\mathbf{a}^{*}$ & $\mathbf{b}^{*}$ & $\mathbf{L}^{*}$ & $\mathbf{a}^{*}$ & $\mathbf{b}^{*}$ \\
\hline $\mathbf{1}$ & $70 \pm 2^{\mathrm{b}}$ & $-0,8 \pm 0,5^{\mathrm{b}}$ & $21,3 \pm 1,5^{\mathrm{a}}$ & $75,7 \pm 1,8^{\mathrm{a}}$ & $-0,14 \pm 0,47^{\mathrm{b}}$ & $25,06 \pm 3,6^{\mathrm{b}}$ \\
$\mathbf{2}$ & $74 \pm 2^{\mathrm{a}}$ & $0,01 \pm 0,29^{\mathrm{b}}$ & $20,4 \pm 0,8^{\mathrm{a}}$ & $78 \pm 3^{\mathrm{a}}$ & $-0,12 \pm 0,35^{\mathrm{b}}$ & $28,9 \pm 2,9^{\mathrm{a}}$ \\
$\mathbf{3}$ & $74 \pm 3^{\mathrm{a}}$ & $2,04 \pm 1,36^{\mathrm{a}}$ & $20,2 \pm 1,7^{\mathrm{a}}$ & $69 \pm 3^{\mathrm{b}}$ & $4,1 \pm 1,8^{\mathrm{a}}$ & $28 \pm 2,5^{\mathrm{ab}}$ \\
\hline
\end{tabular}

$1=$ biofilme de alginato $3 \%$ sem extrato; 2 = biofilme de alginato com extrato; $3=$ controle. Médias seguidas de mesma letra na vertical não diferem estatisticamente entre si, pelo teste tukey $(\mathrm{p} \leq 0,05)$.

Ao avaliar os parâmetros de cor das amostras secas e recobertas, pode-se observar que o parâmetro L* foi similar para os tratamentos de recobrimento com biofilmes de alginato. Entretanto, esses tratamentos diferiram estatisticamente do controle, o que indica que no processo de secagem as amostras de maçã recobertas com alginato, com e sem extrato de laranja apresentaram-se mais próximas da coloração branca do que a amostra controle. Essa diferença pode estar relacionada com 0 brilho, observado visualmente nas amostras recobertas, e pelo fato dos biofilmes formados atuarem como uma barreira de entrada de oxigênio evitando o escurecimento enzimático desencadeado pela enzima polifenoloxidase. Além disso, os biofilmes que foram adicionados de extrato de laranja continham substâncias como compostos fenólicos, carotenoides e vitamina $C$, que poderiam estar evitando a atuação desta enzima, além de auxiliarem na diminuição das reações de escurecimento químico, como a reação de Maillard, devido ação dos antioxidantes presentes no extrato de laranja.

Em relação aos parâmetros $a^{*} \mathrm{e} b^{*}$, pode se observar que todos os tratamentos apresentaram similaridade, ou seja, ambos com a mesma tonalidade da cor amarela e verde. Estes resultados foram semelhantes ao trabalho de MOURA (2007), quando avaliou parâmetros de cor em amostra seca e encontrou valores de $\mathrm{L}^{*}=80,44 \mathrm{a}^{*}=1,50 \mathrm{~b}^{*}=$ $24,94$.

A Figura 1 apresenta a curva de secagem, isto é, a redução da umidade adimensional em base seca, em função do tempo de secagem, para as fatias de maçãs recobertas ou não com os biofilmes.

Figura 1 - Umidade adimensional em base seca (X/Xo bs) das fatias de maçãs recobertas com os biofilmes ou sem recobrimento (controle) em função do tempo de secagem à $60^{\circ} \mathrm{C}$.

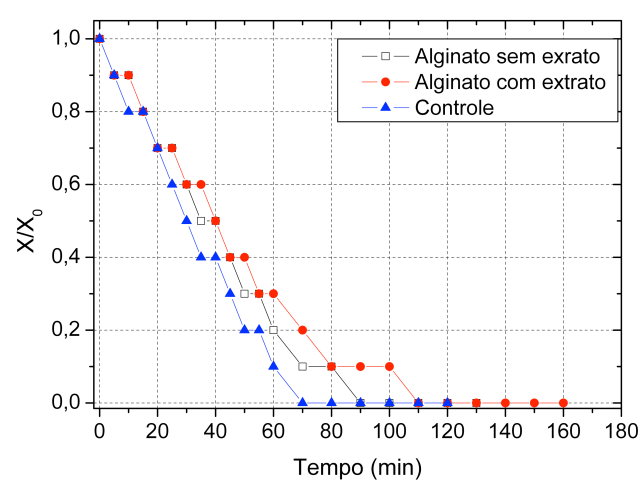


Verificou-se que o recobrimento das fatias de maçãs afetou o tempo do processo de secagem na redução da umidade. Ao comparar os tratamentos com o controle, pode-se observar que o tratamento utilizando alginato de sódio 3\% com e sem extrato de laranja apresentou maior teor de umidade no decorrer da secagem, ou seja, teve menor velocidade de saída da água. Este fato pode ser explicado pela propriedade do biofilme de alginato, em reter a entrada e saída de gases, e água do produto revestido.

\section{CONCLUSÃO}

Os resultados indicaram que a utilização do biofilme de alginato, com ou sem extrato influenciou na secagem, pois quando comparado com o controle, o tempo de processo para atingir a umidade de equilíbrio foi maior. Com isso, o recobrimento da maçã com biofilme desidratada torna o produto atrativo visualmente e de maior valor de mercado uma vez que auxilia na inibição de enzimas oxidativas através da inativação térmica e adição de substâncias redutoras presentes no extrato de laranja.

\section{NOMENCLATURA}

$\begin{array}{ll}\mathrm{E} & \text { ensaios } \\ \mathrm{X} & \text { umidade } \\ \mathrm{X} / \mathrm{X}_{0} & \text { umidade adimensional } \\ \mathrm{Aw} & \text { atividade de água } \\ \mathrm{SSt} & \text { sólidos solúveis totais } \\ \mathrm{pH} & \text { potencial hidrogeniônico } \\ \mathrm{min} & \text { minutos }\end{array}$

\section{REFERÊNCIAS}

AOAC. Official Mathods of Analysis. Washington: Association of Official Analytical Chemists, 1995.
ARAUJO, J. M. A. Química de alimentos: teoria e prática. Viçosa: Ed. Universidade Federal de Viçosa, 2008.

ANDRADE, S. A. C.; GUERRA, T. M. B.; RIBEIRO, M. A.; GUERRA, N. B. Emprego de revestimentos comestíveis de alginato e pectina de baixa metoxilação em alimentos: Revisão. B. CEPPA, Curitiba, v.26, n.1, p.4150, 2008.

BOBBIO, F. O.; BOBBIO, P. A. Introdução À Química De Alimentos. São Paulo: Varela, 2001.

DAMODARAN, S.; PARKIN, K. L.; FENNEMA, O. R. Química de Alimentos de Fennema, Porto Alegre: Artmed, 2010.

ESCOBEDO-AVELLANEDA, Z.; GUTIÉRREZ-URIBE， J.; VALDEZFRAGOSO, A.; TORRES, J. A.; WELTICHANES, J. Phytochemicals and antioxidant activity of juice, flavedo, albedo and comminuted orange. Journal of Functional Foods, v.6, p.470-481, 2014.

FELLOWS, P. J. Tecnologia do processamento de alimentos: princípios e práticas. Porto Alegre: Artmed, 2006.

GOUlARTE, V. D. S.; ANTUNES, E. C.; ANTUNES, P. L. Qualidade de maçã Fuji osmoticamente concentrada e desidratada. Ciência e Tecnologia de Alimentos, v.20, p.160-163, 2010.

IGLESIAS, I.; ECHEVERRÍA, G.; LOPEZ M. L. Fruit color development, anthocyanin content, standard quality, volatile compound emissions and consumer acceptability of several 'Fuji' apple strains. Scientia Horticulturae, v.137, p.138-147, 2012 
INSTITUTO ADOLFO LUTZ. Métodos físico-químicos para análise de alimentos. São Paulo: Instituto Adolfo Lutz, 2008.

\section{LAROTONDA, F. D. S. Biodegradable} films and coatings obtained from carrageenan from Mastocarpus stellatus and starch from Quercus suber. Tese (Doutorado em engenharia de Alimentos) FEUP/Faculdade de Engenharia da Universidade do Porto, 2007

LAZARIDES, H .N.; MITRAKAS, G. E.; MATSOS, K. I. Edible coating and countercurrent product/solution contacting: A novel approach to monitoring solids uptake during osmotic dehydration of a model food system. Journal of Food Engineering, v.82, p.171177, 2007.

LIN, D.; ZHAO, Y. Innovations in the development and application of edible coatings for fresh and minimally processed fruits and vegetables. Comprehensive Reviews in Food Science and Food Safety, v.6, p.60-75, 2007.

LOPES, F. J. Estudo do fenômeno de encolhimento na secagem convectiva de abacaxi com aplicação de micro-ondas. 2013. Dissertação (Mestrado em Produção Vegetal) - Universidade Estadual do Norte Fluminense Darcy Ribeiro, Centro de Ciências e Tecnologias Agropecuárias. Campos dos Goytacazes, Rio de Janeiro, 2013.

LOPES, J. C. Aproveitamento da maçã industrial (Pirus malus, L.) da região de Guarapuava -PR para produtos alimentícios utilizando tecnologia simplificada. 2011. Dissertação (Mestrado em Tecnologia) - Universidade Federal do Paraná, Curitiba, Paraná, 2011
LU, Y.; YEAP FOO, L. Antioxidant and radical scavenging activities of polyphenols from apple pomace. Food Chemistry, v.68, p.81-85, 2000.

LUPETTI, K. O.; CARVALHO, L. C.; MOURA, A. A.; FATIBELLO-FILHO, O. Análise de imagem em química analítica: empregando metodologias simples e didáticas para entender e prevenir o escurecimento de tecidos vegetais. Química Nova, v.28, p.548554, 2005.

MELO, E. A.; MACIEL, M. I. S.; LIMA, V. L. A. G.; NASCIMENTO, R. J. Capacidade antioxidante de frutas. Brazilian Journal of Pharmaceutical Sciences, v.44, p.193-201, 2008.

MORENO, J.; SIMPSON, R.; PIZARRO, N.; PAVEZ, C.; DORVIL, F.; PETZOLD, G.; BUGUEÑO, G. Influence of ohmic heating/osmotic dehydration treatments on polyphenoloxidase inactivation, physical properties and microbial stability of apples (cv. Granny Smith). Innovative Food Science and Emerging Technologies, v.20, p.198207, 2013.

MOURA, S. C. S. R.; BERBARI, S. A.; GERMER, S. P. M.; ALMEIDA, M. E. M.; FEFIM, D. A. Determinação da vida-deprateleira de maçã-passa por testes acelerados. Ciências e Tecnologia de Alimentos. v.27, p.141-148, 2007.

PEREIRA, N. R. Estudo da aplicação de micro-ondas na secagem de bananas tratadas osmoticamente. 2007. Tese (Doutorado em Engenharia de Alimentos) Universidade Estadual de Campinas, São Paulo, 2007.

RAGHAVAN, G. S. V.; RENNIE, T. J.; SUNJKA, $\quad$ P. $\quad$ S.; ORSAT, V.; PHAPHUANGWITTAYAKUL, W.; 
TERDTOON, P. Overview Of New Techniques For Drying Biological Materials With Emphasis On Energy Aspects. Brazilian Journal of Chemical Engineering, v. 22, p. 195-201, 2005.

SANTOS, M. L.; MACHADO, A. V.; ALVES, F. M. S.; COSTA, A. P. L. M. (2013). Estudo físico-químico de maçã desidratada em secador convectivo. Revista Verde de Agroecologia e Desenvolvimento Sustentável, v.8, p.30-37, 2013.

SELMO, M. S.; TREPTOW, R. O.; ANTUNES, P. L. Avaliação físico-química e sensorial de maçãs (Malus doméstica, borkh.) branqueadas em micro-ondas e desidratadas. Revista Brasileira de Agrociência, v.2, p.3338, 1996.

TACO. Tabela Brasileira de Composição de Alimentos. Campinas, NEPA UNICAMP 2011.

TOMÁS-BARBERÁN, F. A.; ESPÍN, J. C. Phenolic compounds and related enzymes as determinants of quality in fruits and vegetables. Journal Science Food Agriculture, v.81, p.853-879, 2001.

\section{AGRADECIMENTOS}

Os autores agradecem à FAPERJ, CNPq, CAPES e UENF pelas bolsas de estudo associados a este trabalho e pelo apoio financeiro. À Professora Nádia Rosa Pereira pela ajuda e incentivo. 